\title{
Influence of rock mass veining and non-persistent joints on secondary fragmentation during block caving
}

\author{
L Dorador The University of British Columbia, Canada \\ E Eberhardt The University of British Columbia, Canada \\ D Elmo The University of British Columbia, Canada
}

\begin{abstract}
Reliable estimates of rock mass fragmentation are essential for pre-feasibility and feasibility-level assessments of drawpoint productivity in the planning of a block caving operation. The last stage of this fragmentation process is known as secondary fragmentation; secondary fragmentation is not well understood due to its complexity and the numerous influencing factors involved, but it plays a major role in the design and success of a caving operation. One of these factors is the strength of the rock blocks, for which the presence of planes of weakness in the form of veining and non-persistent joints is of special interest given the significant influence it potentially has on the overall fragmentation process.

This paper summarises the results from a series of detailed experiments investigating the influence of soft veins and small discontinuities (i.e. defects) on the fragmentation characteristics of broken ore. Vein thickness (or joint opening) is shown to be a key parameter since thicker defects trigger a different fragmentation mechanism compared to thin defects. In terms of defect orientation, those aligned with the vertical loading direction were seen to contribute to fragmentation through simple splitting of the blocks. Conversely, block defects aligned perpendicular to the vertical loading direction promoted increased fragmentation through compressive failure. Of interest is that under a dense initial packing; the effect of defects is such that blocks with high matrix strengths that include defects showed comparable levels of fragmentation to blocks with matrix strengths several times weaker without defects. It is expected that these experimental results, together with advanced numerical models capable of explicitly modelling fragmentation (e.g. finite element methoddiscrete element method approach), would allow for the influence of block veining and non-persistent joints to be included in secondary fragmentation assessments for block caving operations.
\end{abstract}

Keywords: block caving, secondary fragmentation, laboratory testing, block veining

\section{Introduction}

Reliable estimates of rock mass fragmentation are essential in the planning of a block caving operation. It is well-accepted that the broken ore extracted at the drawpoints is dependent on a fragmentation process which incorporates three stages: (i) in situ fragmentation, representing the natural discrete fracture network distributed throughout the rock mass, (ii) primary fragmentation, arising from stress-induced fractures propagating in the cave back, and (iii) secondary fragmentation, which first involves rockfall impact onto the muck pile surface (when an airgap is present) and then splitting and rounding of the blocks (broken ore) as they move downwards through the draw column towards the drawpoint (Laubscher 1994; Eadie 2003). With regards to secondary fragmentation, it plays a major role in the design and success of a caving operation. Despite this, it is the least understood fragmentation stage due to the numerous factors and complex mechanisms involved in this process. This paper summarises a set of detailed experiments reported in the $\mathrm{PhD}$ thesis by Dorador (2016), which focuses on the secondary fragmentation of broken ore that occurs within the central plug flow compression zone of a draw column. This is differentiated from the outer shear band zones that also develop (Figure 1). 
The broken ore within a draw column might involve a mixture of blocks with different lithological origins. Hence, individual blocks with different strengths will interact and contribute differently to the overall secondary fragmentation observed at the drawpoint; i.e. weaker blocks will undergo more fragmentation than stronger blocks. Also contributing to strength heterogeneity is the presence of small-scale discontinuities and veins (defects), which can significantly influence the secondary fragmentation of broken ore. Two key defect characteristics affecting secondary fragmentation are examined in this work.

- Defect orientation: It is hypothesised that block defects (veins/discontinuities) aligned with the primary loading direction, as well as at point loads that develop at corner contacts with adjacent blocks, would promote easy splitting along the defect, resulting in a small number of moderately smaller blocks. Conversely, block defects aligned perpendicular to the applied stress would promote compressive failure (crushing, shearing, etc.) requiring higher stress magnitudes, resulting in increased fragmentation as reported by Dorador et al. (2015).

- Defect thickness: As noted by Brzovic and Villaescusa (2007), rock veins are clearly comprised of an altered halo surrounding the vein infill. They found that vein thicknesses greater than $2 \mathrm{~mm}$ tend to significantly increase the fragmentation of caved rock blocks.

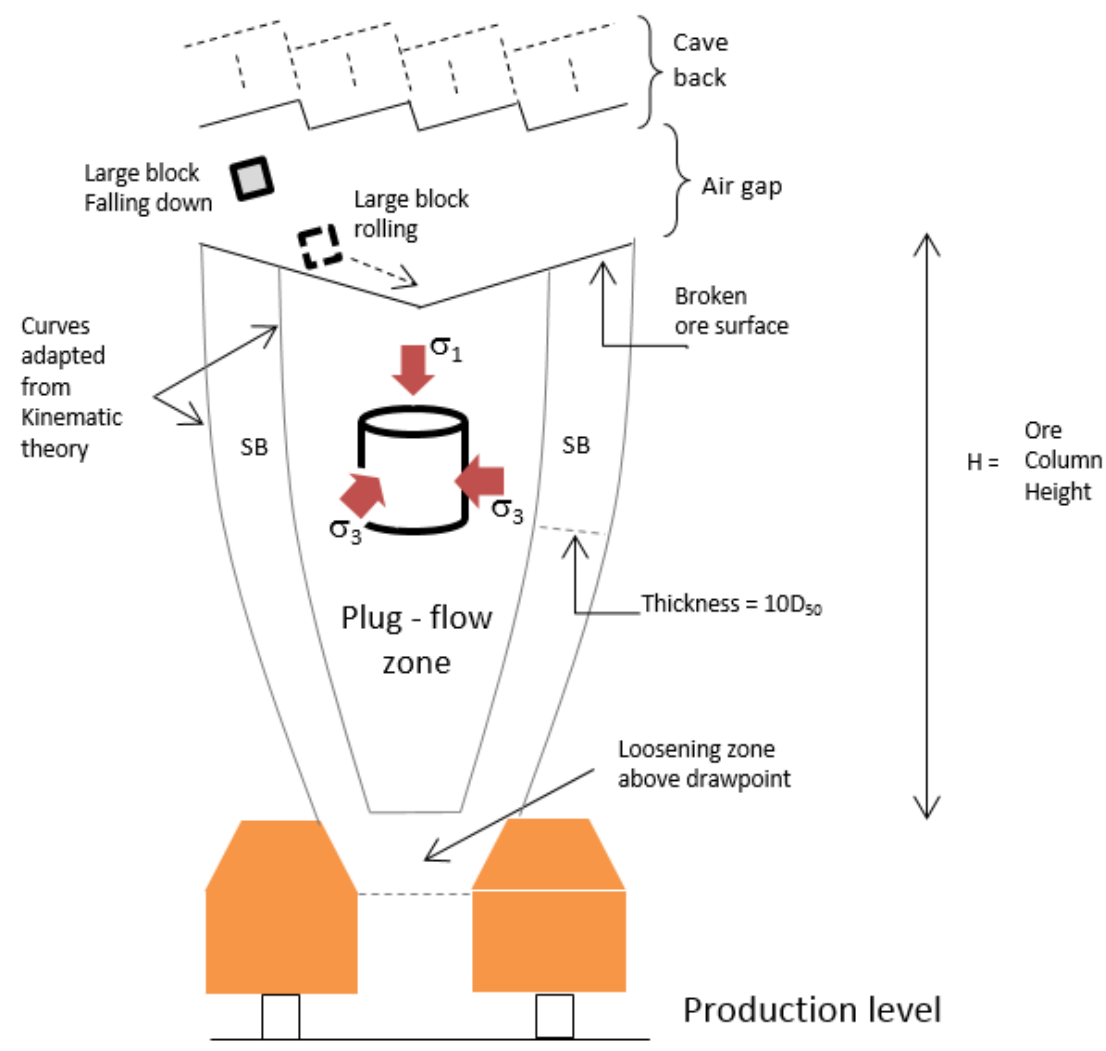

Figure 1 Conceptualisation of a draw column, showing the plug flow compression and shear band zones that develop

\section{$2 \quad$ Laboratory testing}

\subsection{Set-up and apparatus}

A series of vertical loading compression tests were carried out to simulate the secondary fragmentation of broken ore in the central compressive plug flow zone of a draw column (Figure 1). These tests were performed using a standard proctor compression mould, which was loaded using a Wykeham Farrance WF-5562s deformation-controlled machine. Proctor moulds are typically used for assessing the relationship between moisture content and density in fine soils (ASTM International 2010), but in this case was used as a compression cell, which allows vertical deformation but restricts horizontal deformation (Figure 2). 


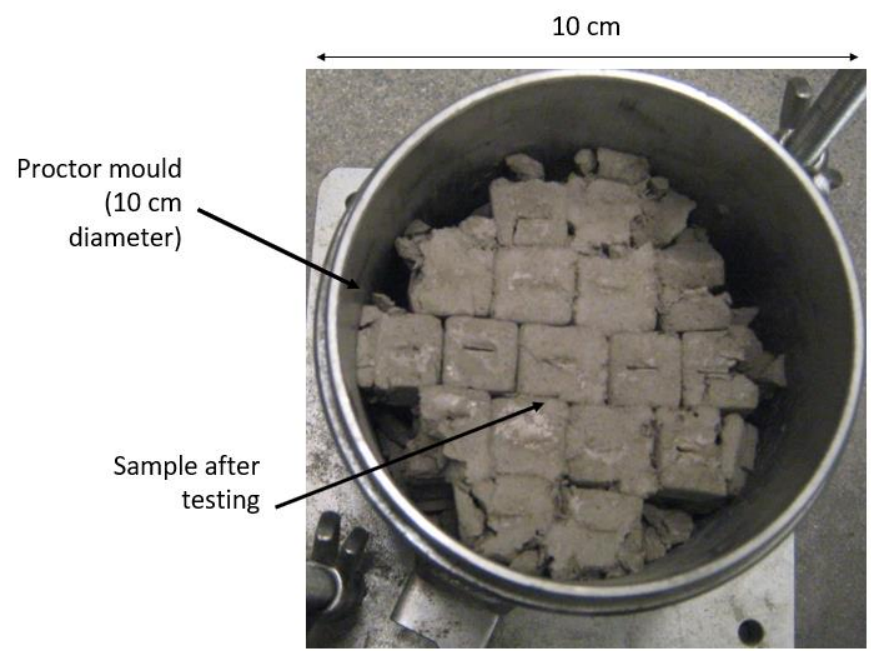

(a)

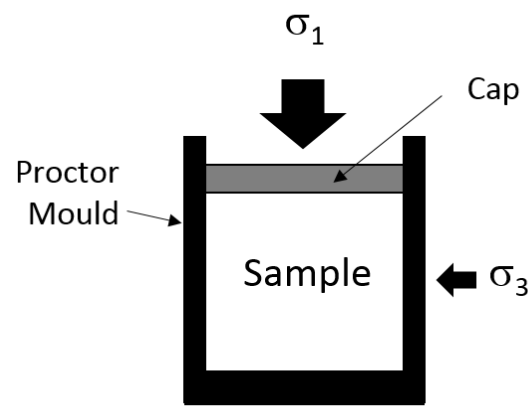

(b)

Figure 2 (a) Specimen after testing, for dense (tidy) packing set-up; and, (b) Sketch of proctor mould and sample

The ratio of mould height to diameter was maintained between 0.6 and 0.7 to decrease arching due to side friction acting on the specimens. The testing configuration allowed the vertical stress to be controlled; this was equated to the draw column height. The confining stress acting in the horizontal plane develops passively as vertical loading is applied, due to the rigid cell walls. Thus, the 1D test set-up was considered as a practical and efficient means to empirically study secondary fragmentation within the compression/plug flow zone (Dorador 2016).

More than 2,500 concrete cubes were fabricated and tested to simulate broken ore, carefully controlling their size and intrinsic strengths. Subgroups of these included a small, non-persistent discontinuity, grouped according to the length, orientation and thickness of the defect to examine the role of small joints and veining on secondary fragmentation. Broken ore packing density was also controlled during testing and a total porosity of 0.36 (representing a tidy dense packing) was defined for testing. The deformation rate applied in the tests was $0.5 \mathrm{~mm} / \mathrm{min}$ and the final vertical deformation varied for each test between 4.6 and $43 \%$. Considering the inherent heterogeneity of the blocks making up the broken ore material in a draw column, any applicable parametric study would benefit from minimising the degree of material variability and enabling such key parameters as sample strength, shape, size and/or packing to be controlled during testing. This advantage of using a fabricated material offered more uniformity and control in material properties and characteristics, compared to using actual rock sampled from a caving operation.

To manufacture the cubes, a variety of steel tubing moulds with different lengths, widths and heights were utilised (Figure 3). Mixes of cement (C), sand (S), and water (W) were used in proportions of 1.75:2.2:1 (C:S:W) and two kinds of Lafarge early strength cement were used ( $C 1$ and $C 2$ ). The procedure to prepare the concrete cubes included the following steps. First, the cement, sand and water mixture was placed in an open tray. Next, the interior wall of the mould was greased using cooking oil and pressed into the mixture. The excess mix was then removed, and the mould was left in place for approximately two hours to allow the concrete to partially set before being removed. Finally, the cubes were removed from the steel mould and cured under controlled temperatures $\left(19-21^{\circ} \mathrm{C}\right)$ and humidity $(50-70 \%)$ for between two and three days. Sample groups were colour tinted for visual observation purposes. Quality control was conducted under point load testing (ASTM International 2016) of cubes randomly sampled from each batch. A set of cubes ready for testing is shown in Figure 4.

For the purpose of this paper, the results presented focus on the tests performed involving cube sizes of $1.7 \times 1.7 \times 1.7 \mathrm{~cm}$. These are intended to represent block sizes of $0.5 \mathrm{~m}$ and larger, which are realistic sizes for blocks within a compression zone. More details about the sample preparation and testing can be found in Dorador (2016). 


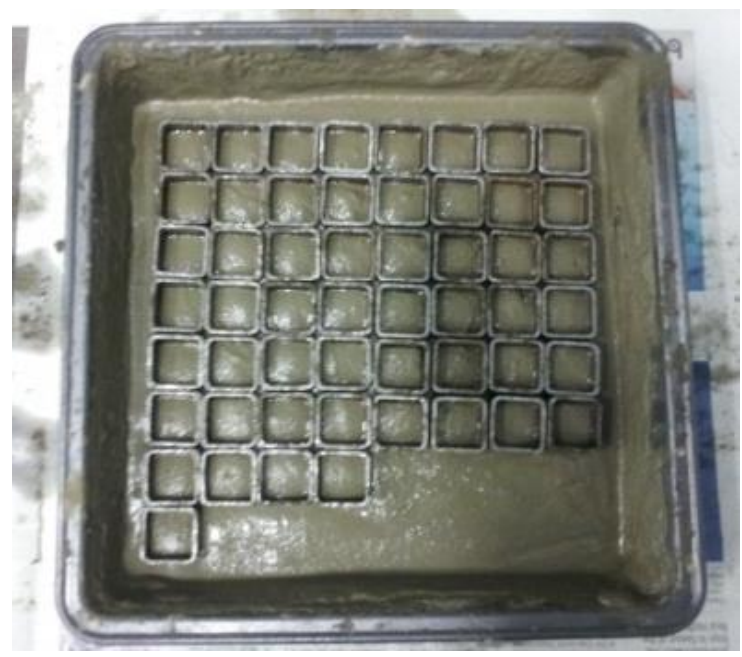

Figure 3 Example of steel mould pressed into the concrete mix for preparation of $1.7 \mathrm{~cm}$ edge length cubes

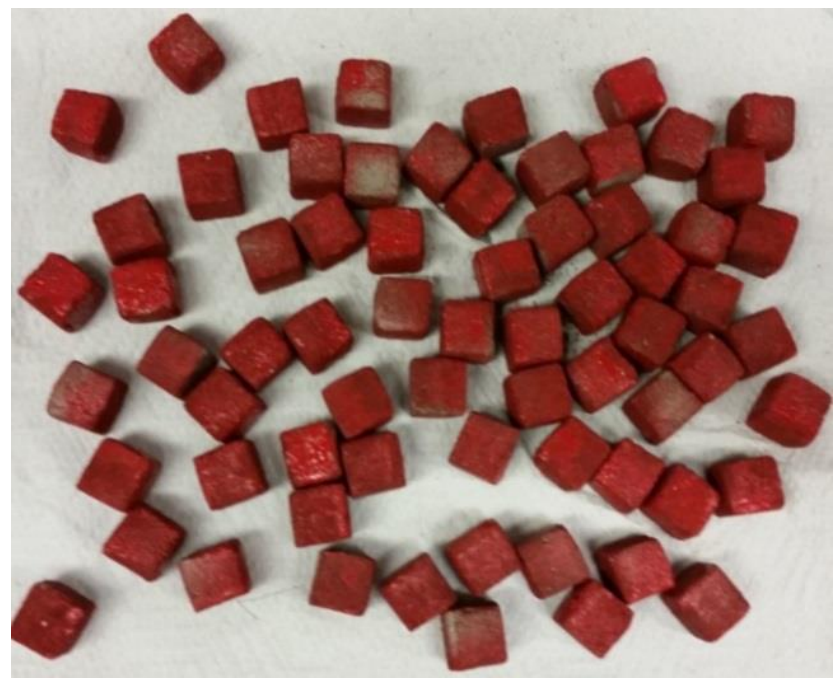

Figure 4 Prepared cubes after curing and ready for testing $(1.7 \mathrm{~cm}$ edge length cubes)

\subsection{Intrinsic cube strengths}

Different intrinsic cube strengths were obtained using different mixes of the early strength concrete. Point load testing (PLT) of cubes (1.7 cm edge length) prepared using standard mix proportions (C:S:W = 1.75:2.2:1) with the $\mathrm{C} 1$ and $\mathrm{C} 2$ cements returned mean strength values of 3.10 and $2.28 \mathrm{MPa}$, respectively (Table 1). Sugar cubes were added as a test material (tests T-17 to T-23) to provide an alternative low-strength material $(\mathrm{PLT}=0.42 \mathrm{MPa})$. These were slightly smaller in size $(1.5 \times 1.5 \times 1.5 \mathrm{~cm})$ to the concrete cubes tested $(1.7 \times 1.7 \times 1.7 \mathrm{~cm})$. A summary of the mechanical properties of the concrete cubes is presented in Table 2 . In addition to the point load tests, four uniaxial compressive strength tests (ASTM International 2014) were carried out on the C2 concrete mix, for which a mean UCS value of $31 \mathrm{MPa}$ was obtained.

Table 1 Strength classes of concrete cubes tested based on PLT

\begin{tabular}{llllll}
\hline $\begin{array}{l}\text { Strength } \\
\text { class }\end{array}$ & $\begin{array}{l}\text { No. of PLT } \\
\text { conducted }\end{array}$ & $\begin{array}{l}\text { Mix characteristics } \\
\text { (cement:sand:water) }\end{array}$ & $\begin{array}{l}\text { Type of } \\
\text { cement }\end{array}$ & $\begin{array}{l}\text { Mean } \\
\text { PLT }\end{array}$ & $\begin{array}{l}\text { Standard deviation } \\
\text { (MPa) }\end{array}$ \\
\hline Standard & 690 & $1.75: 2.2: 1$ & C1 & 3.10 & 0.49 \\
& & C2 & 2.28 & 0.33 \\
\hline
\end{tabular}


Table 2 List of tests on regular cube samples without embedded veins

\begin{tabular}{lll}
\hline Test no. & Material & Point load strength (MPa) \\
\hline T-1 to 16 & Cement - C1 strength cement & 3.10 \\
T-17 to 23 & Sugar cube & 0.42 \\
T-24 to 26 & Cement - C2 strength cement & 2.28 \\
\hline
\end{tabular}

\section{Testing procedure and quantification of fragmentation}

The vertical loading compression testing program included sample mixes involving cubes without and with embedded small defects and either $\mathrm{C} 1$ or $\mathrm{C} 2$ concrete strengths. Embedded defects, representing veins and/or small joints, were included within the concrete cubes by pressing a thin piece of cardboard into the wet concrete before it set. After curing, the cardboard pieces were removed from the concrete cubes, leaving an open gap. Both the defect trace lengths $(8$ or $16 \mathrm{~mm}$ ) and orientation relative to loading (horizontal or vertical) were tested (Figure 5). The depth of the defects for each sample was set at $17 \mathrm{~mm}$ (i.e. they penetrated completely through the cube). Details are provided in Tables 2 and 3.

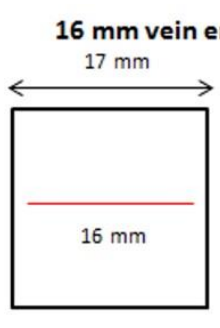

PLAN

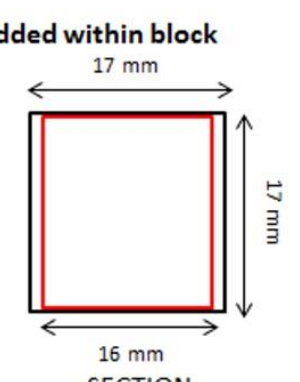

SECTION

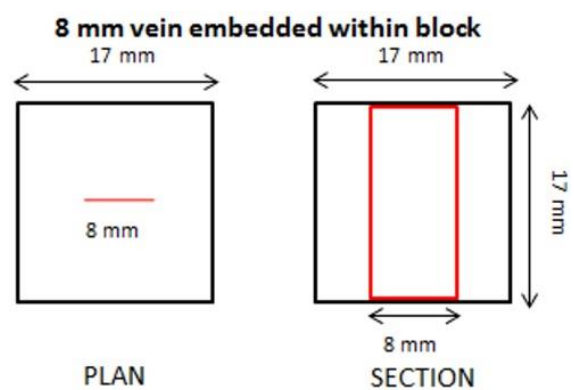

PLAN
SECTION

Figure 5 Plan and section view of cubes with embedded defects (i.e. soft veins or small joints)

Table 3 Tests on concrete cubes with embedded defects

\begin{tabular}{lllll}
\hline $\begin{array}{l}\text { Sample } \\
\text { no. }\end{array}$ & $\begin{array}{l}\text { Concrete strength } \\
\text { (MPa) }^{*}\end{array}$ & $\begin{array}{l}\text { Defect width } \\
(\mathbf{m m})\end{array}$ & $\begin{array}{l}\text { Defect } \\
\text { thickness }(\mathbf{m m})\end{array}$ & $\begin{array}{l}\text { Defect } \\
\text { orientation }\end{array}$ \\
\hline T-27 to 29 & 3.10 & 8.0 & 0.3 & Vertical \\
T-30 to 32 & 3.10 & 16.0 & 0.3 & Vertical \\
T-33 to 34 & 3.10 & 8.0 & 0.3 & Horizontal \\
T-35 to 36 & 3.10 & 16.0 & 0.3 & Horizontal \\
T-37 & 2.28 & 16.0 & 0.02 & Vertical \\
T-38 & 2.28 & 16.0 & 0.1 & Vertical \\
T-39 & 2.28 & 16.0 & 0.3 & Vertical \\
T-40 & 2.28 & 16.0 & 0.02 & Horizontal \\
T-41 & 2.28 & 16.0 & 0.3 & Horizontal \\
\hline
\end{tabular}

*Point load strength of concrete mix used (Table 1)

In order to quantify particle fragmentation associated with the vertical loading compression testing, the Hardin's relative breakage index $\mathrm{Br}$ was adopted. This index is obtained as follows: (i) the initial and final size distributions from the compression test are plotted as a cumulative passing percentage, (ii) the area between these two size distribution curves is calculated, which represents the total fragmentation $\left(B_{t}\right)$ of the sample after testing (Figure 6), (iii) the potential fragmentation $\left(B_{p}\right)$ is assessed using the area between a vertical line 
drawn at $d=0.075 \mathrm{~mm}$ and the initial size distribution curve (Figure 7), and (iv) the relative breakage $\left(\mathrm{B}_{\mathrm{r}}\right.$ ) is finally calculated as the ratio of these two terms:

$$
B r=\frac{B t}{B p}
$$

A higher $\mathrm{Br}$ ratio indicates a higher degree of fragmentation, a value of zero indicates no fragmentation, and a value of 1 represents the maximum theoretical fragmentation.

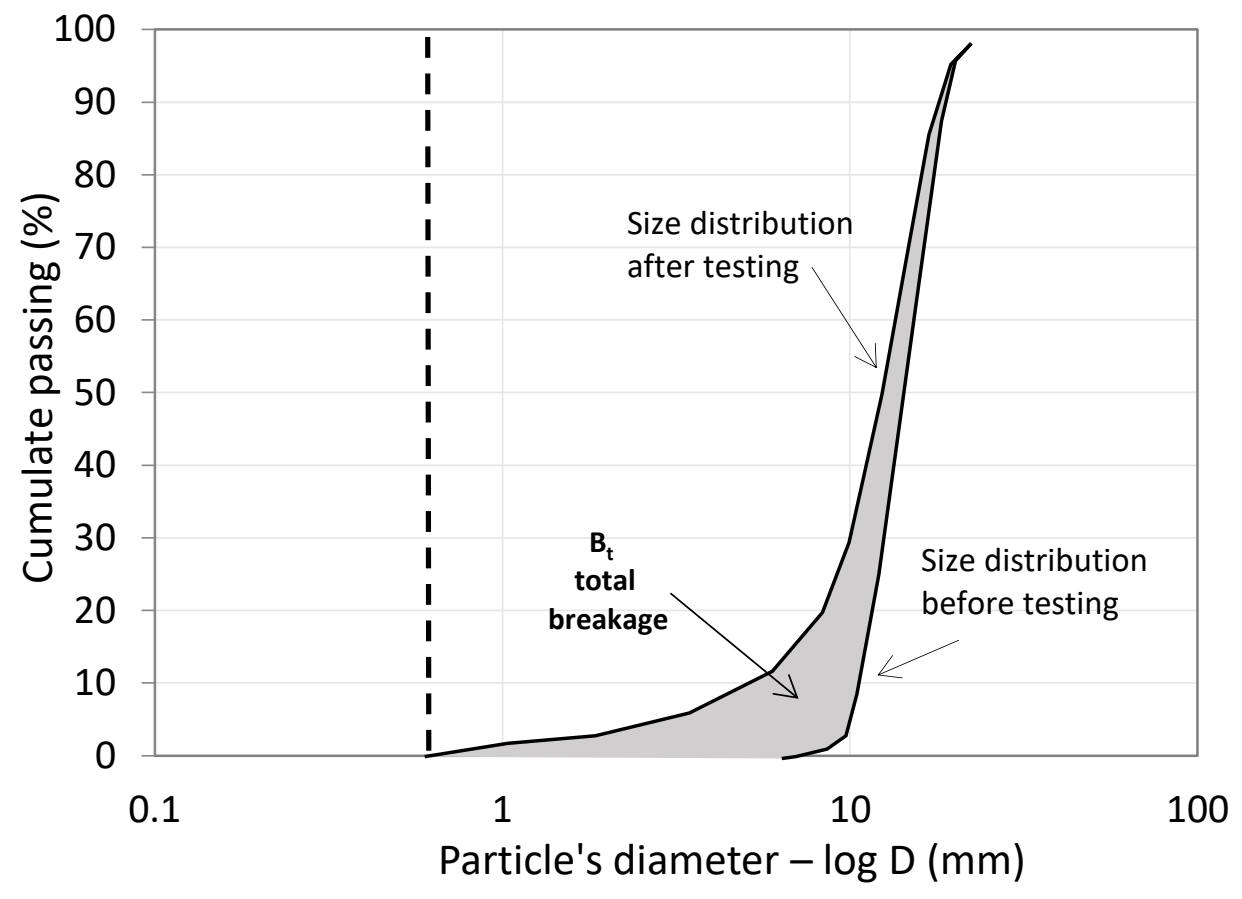

Figure 6 Assessment of the total breakage $\left(B_{t}\right)$ parameter introduced by Hardin (1985)

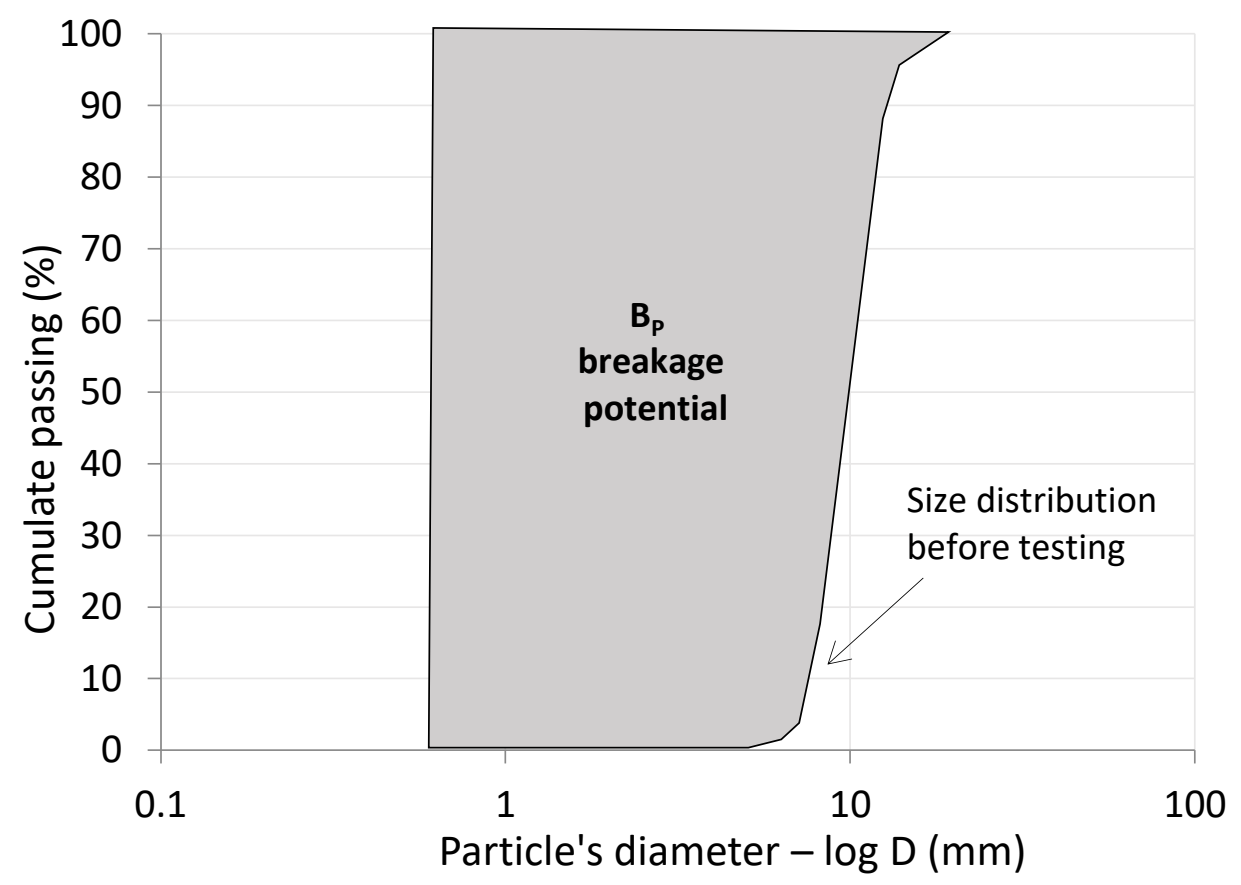

Figure 7 Assessment of the breakage potential $\left(B_{p}\right)$ parameter introduced by Hardin (1985) 
The size distribution after testing was estimated by weighing each fragment rather than sieving them (to avoid further damage and breakage), an approach permitted because both size and weight are directly proportional given the use of a controlled material (i.e. concrete). Thus, after weighing each fragment, the particle volume is obtained based on material density (approximately $2 \mathrm{~g} / \mathrm{cm}^{3}$ ), and the equivalent particle diameter is obtained assuming the volume of a sphere. The minimum equivalent particle diameter cutoff below which particles were not individually measured was $0.66 \mathrm{~cm}$ (these were treated as fines). Given that the measured maximum post-test diameters were equal to the initial size $(1.7 \mathrm{~cm})$, the maximum to minimum particle diameter ratio used to evaluate $B_{r}$ was 3.2. Figure 8 presents two examples of particle size distributions obtained after testing (specifically, T-26 and T-34) and the equivalent $\mathrm{B}_{r}$ for each test.

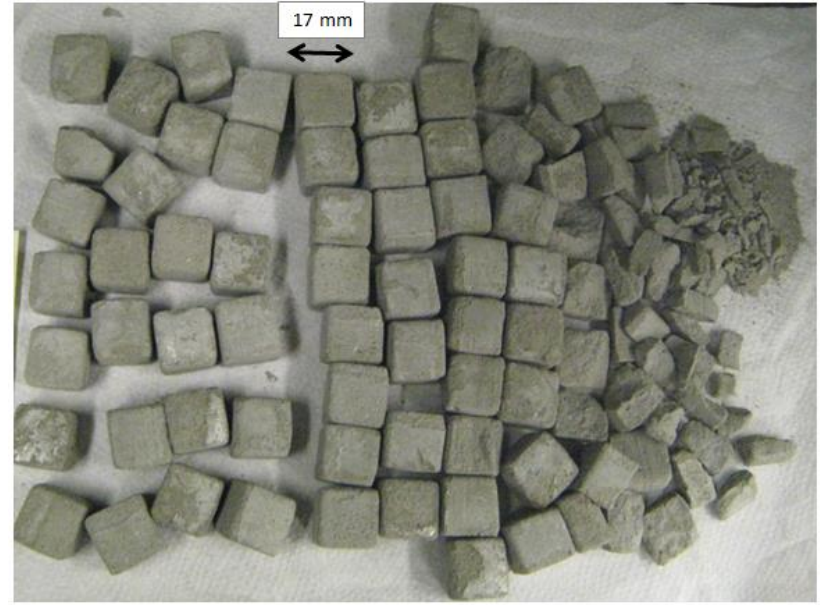

(a)

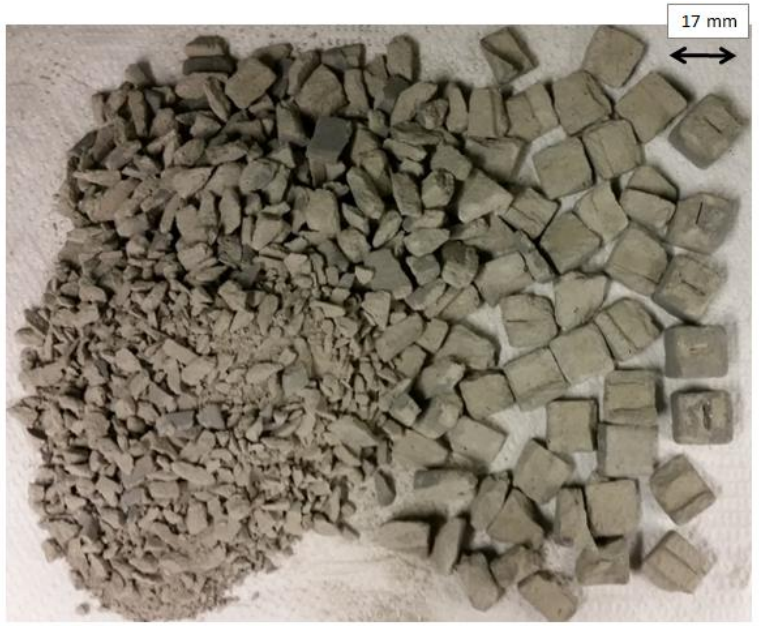

(b)

Figure 8 Comparison of size distributions after vertical compression testing for tests samples; (a) Without the embedded defects; and, (b) With the embedded defects

\section{$4 \quad$ Results}

The test results showed that non-persistent open joints and soft veins embedded within blocks can significantly affect secondary fragmentation, especially in stronger rocks. Figure 9 shows the results from several series of tests in terms of the energy $(\mathrm{E})$ input applied to the sample (i.e. work) and the corresponding fragmentation parameter $B_{r}$. The results show that embedded defects promote higher fragmentation (the black line represents results for cubes without a defect). However, comparison of the results for the 8 and $16 \mathrm{~mm}$ defect lengths indicate that there is little noticeable difference in fragmentation, thus suggesting that defect length relative to the block size is a less sensitive parameter for these $1 \mathrm{D}$ vertical loading compression test results.

In contrast, a noticeable difference in fragmentation was observed in terms of defect orientation. Vertical defects, aligned parallel with the vertical loading direction, resulted in less fragmentation than defects aligned horizontally (i.e. perpendicular to the loading direction). This corroborates findings by Dorador et al. (2015) that vein orientation serves to promote different secondary fragmentation mechanisms, where loading parallel to the vein results in block splitting, which limits further fragmentation, whereas loading perpendicular to the vein results in compressive shear failure of the block, resulting in more (and therefore smaller) fragments. Note that these testing results apply to dense (tidy) broken ore packing under vertical loading compression. 


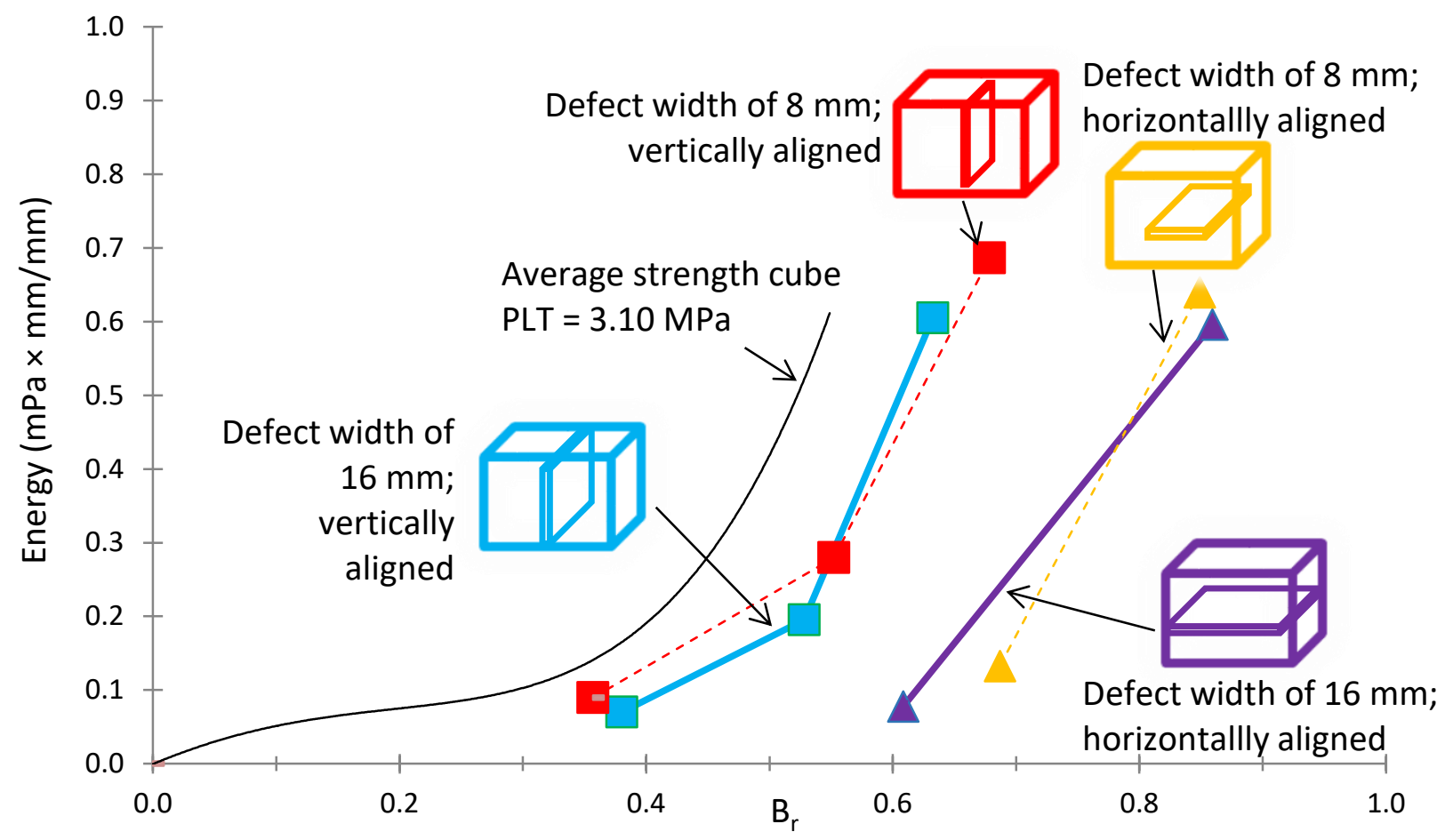

Figure 9 Fragmentation test results investigating the influence of embedded defects and their orientation. Note the black line represents the trend for cubes without an embedded defect for comparison

To corroborate these results, four graphs are included in Figure 10. These compare two cases of small and large defects, aligned either vertically (Figures 10(a) and (b)) or horizontally (Figures 10(c) and (d)). In each case, the standard cube samples (dashed curves) show much lower fragmentation than cubes samples with embedded defects under comparable vertical loads $\left(\sigma_{\mathrm{v}}\right)$. Of interest are the shapes of the post-test size distribution curves. For samples without an embedded defect, the fragmentation curves (dashed black lines in each plot) show a uniform post-test size distribution, which is commonly observed in 1D compression testing. However, this trend was not observed in the samples with embedded defects. Instead, these showed gaps in the larger particle sizes.

It should be noted that the defect gap thickness in these tests was $0.3 \mathrm{~mm}$, which is large relative to the cube's edge length $(17 \mathrm{~mm})$. Based on this, two additional defect gap thicknesses $(0.1$ and $0.03 \mathrm{~mm})$ were analysed, with data shown in Figure 11. For these later tests, the ratio between the tightest defect thickness $(0.03 \mathrm{~mm})$ and cube edge length more closely approximates those found in actual blocks; e.g. a $2 \mathrm{~mm}$ vein thickness found in block sizes of $1 \mathrm{~m}$ edge length (Brzovic \& Villaescusa 2007). The results indicate that higher fragmentation develops for larger soft vein thicknesses, regardless of whether the veins are loaded vertically or horizontally. However, vein thickness was seen to be less important than the orientation of the veins themselves.

Comparing the different experimental results, it was found that tests with horizontally embedded defects and those with lower cube strengths generated the greatest fragmentation. An upper bound on fragmentation (i.e. maximum) was obtained in tests performed on sugar cubes, which are several times weaker than the concrete cubes without defects. As can be observed in Figure 12, similar values are obtained under low loading conditions (i.e. around $0.1 \mathrm{MPa} \cdot \mathrm{mm} / \mathrm{mm}$ ) but then diverge at higher values, with the embedded defect results following trends between the weaker sugar cubes and stronger concrete cubes without defects. Thus, the increased fragmentation seen for the horizontally embedded defects is not simply due to compressive failure as would also be experienced by the concrete cubes without defects, but is influenced by the presence of the defect. 


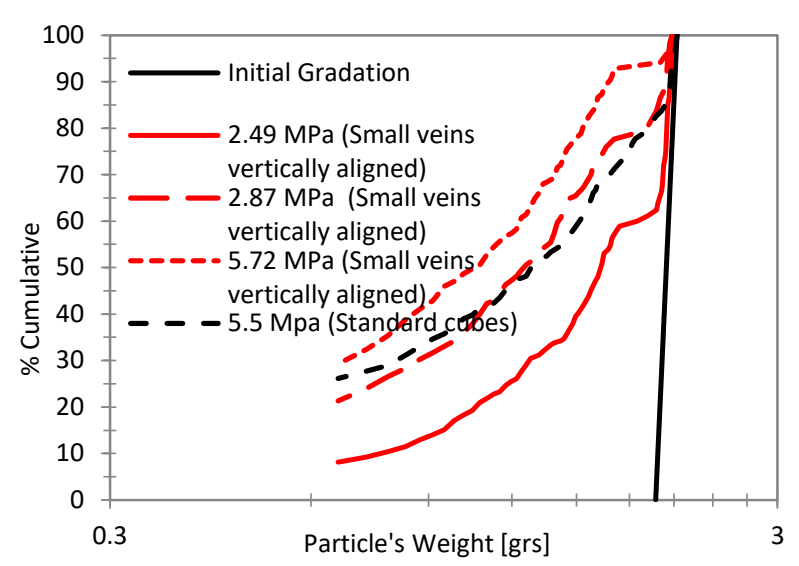

(a)

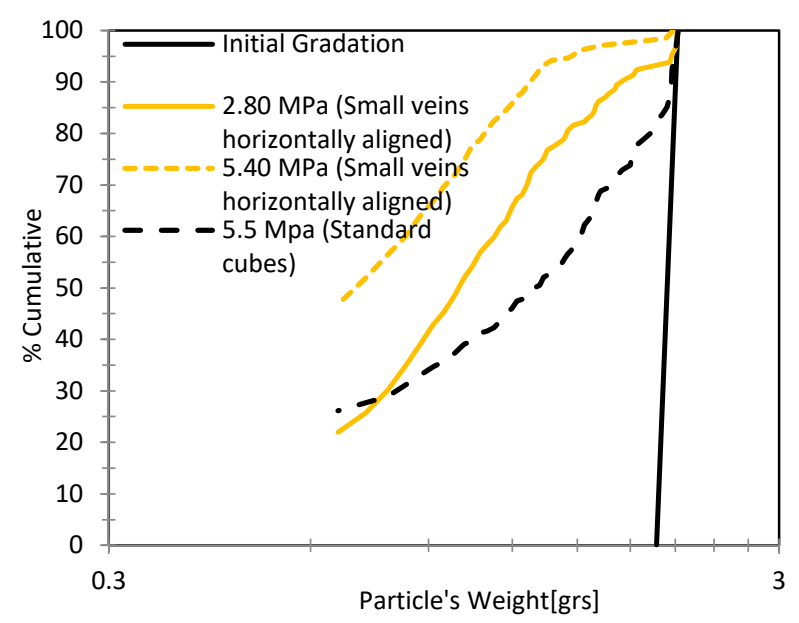

(c)

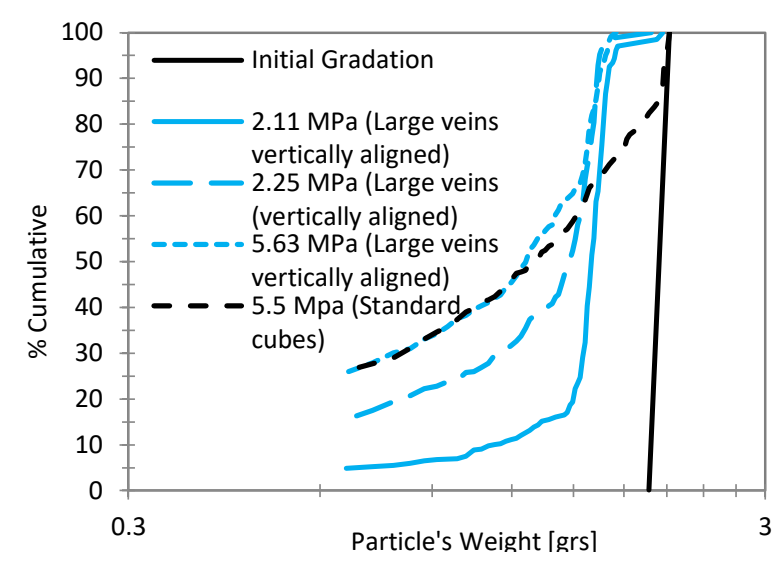

(b)

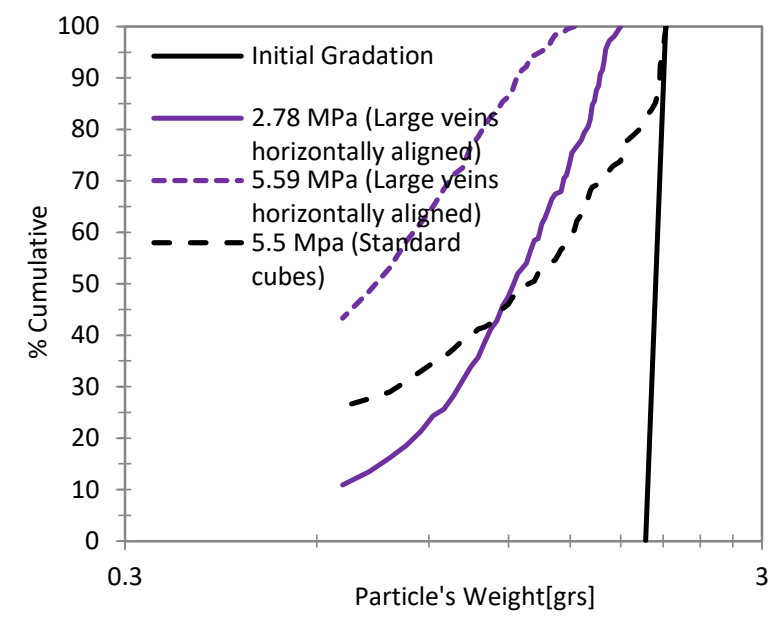

(d)

Figure 10 Fragmentation comparison with block size distributions before and after testing. (a) Small defect (i.e. soft vein) vertically aligned; (b) Large defect vertically aligned; (c) Small defect horizontally aligned; and, (d) Large defect horizontally aligned

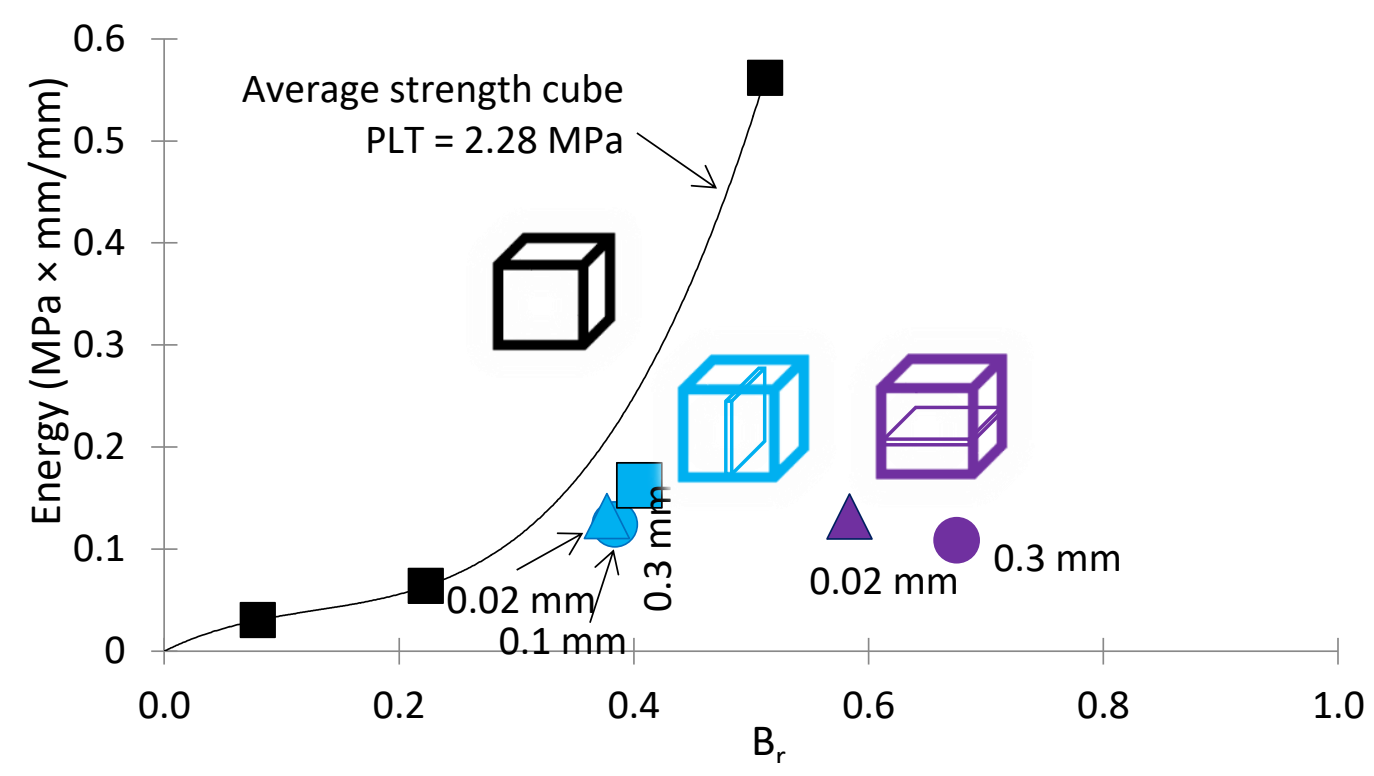

Figure 11 Fragmentation test results investigating the influence of embedded defect thickness 


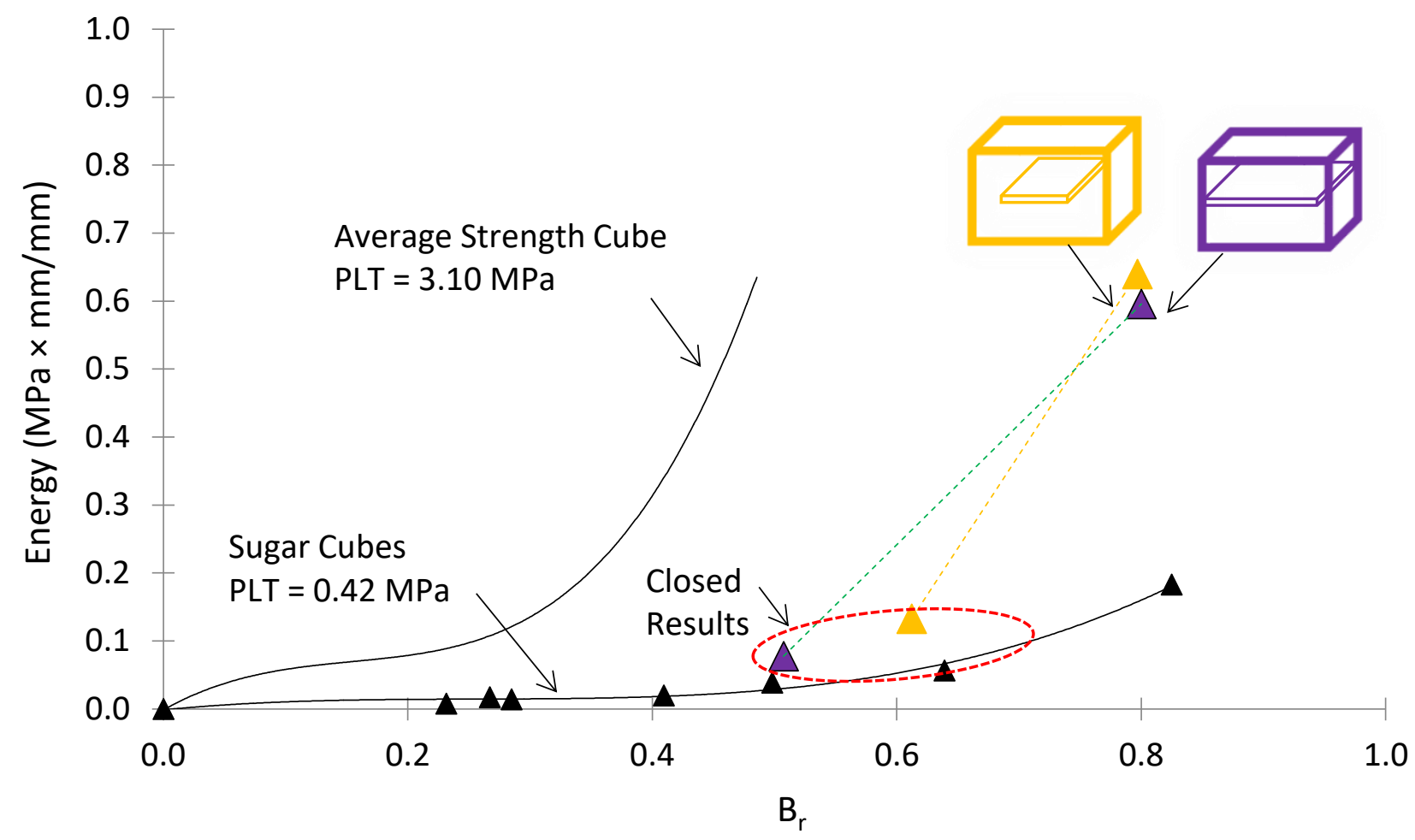

Figure 12 Fragmentation test results showing results for cubes with and without an embedded defect

\section{Conclusion}

Secondary fragmentation is a key topic requiring further research if the next generation of larger and deeper caving operations will meet with success. Experimental investigations provide a means to address certain knowledge gaps and improve existing empirical and numerical approaches to evaluating secondary fragmentation during block caving. Reported here was a subset of results from a larger experimental study consisting of 41 small-scale vertical loading compression tests performed on concrete cuboids, designed to simulate broken ore (caved rock) moving down through the plug flow compression zone of a draw column. The tests reported here were specific to those comparing the fragmentation of cuboids with a small embedded defect, representing a soft vein or non-persistent discontinuity, to those without. Varied were the defect length, orientation and aperture to examine the role of small joints and veining on secondary fragmentation processes.

Defect thickness was shown to be a key parameter because thicker defects resulted in a different fragmentation mechanism compared to thin defects. In terms of defect orientation, those aligned with the loading direction contributed to fragmentation through splitting of the blocks. Conversely, block defects aligned perpendicular to the loading direction promoted increased fragmentation through compressive failure (crushing and shear). Defect orientation relative to loading in the draw column is of course random, although possibly less so if there is a pervasive veining direction and a dense initial packing. The effect of embedded defects is such that blocks with enhanced strength (7x), but including embedded defects, showed comparable levels of fragmentation to weaker blocks without embedded defects. The characterisation of veining intensity using discrete fracture network modelling techniques may be an attractive means to provide input using the empirical charts developed to assess secondary fragmentation occurring within the compression zone (plug flow zone) in an isolated movement zone. As this work is focused on soft veins or open joints without infill, more empirical and numerical analysis examining vein infill stiffness is required to fully understand the influence of rock mass veining and defects on secondary fragmentation during block caving. 


\section{Acknowledgement}

This work was carried out with logistical support and funding provided by Codelco Underground Chuquicamata (PMCHS), Golder Associates, and a Natural Sciences and Engineering Research Council of Canada Collaborative Research and Development Grant.

\section{References}

ASTM International 2010, ASTM D698: Standard Test Methods for Laboratory Compaction Characteristics of Soil Using Standard Effort (12 $\left.400 \mathrm{ft}-\mathrm{lbf} / \mathrm{ft}^{3}\left(600 \mathrm{kN}-\mathrm{m} / \mathrm{m}^{3}\right)\right)$, ASTM International, West Conshohocken.

ASTM International 2014, ASTM D7012: Standard Test Methods for Compressive Strength and Elastic Moduli of Intact Rock Core Specimens Under Varying States of Stress and Temperatures, ASTM International, West Conshohocken.

ASTM International 2016, ASTM D5731: Standard Test Method for Determination of the Point Load Strength Index of Rock and Application to Rock Strength Classifications, ASTM International, West Conshohocken.

Brzovic, A \& Villaescusa, E 2007, 'Rock mass characterization and assessment of block-forming geological discontinuities during caving of primary copper ore at the El Teniente mine, Chile', International Journal of Rock Mechanics and Mining Sciences, vol. 44, no. 4, pp. 565-583.

Dorador, L, Eberhardt, E \& Elmo, D 2015, 'Influence of block strength and veining on secondary fragmentation related to block caving', Proceedings of the 13th International Congress of Rock Mechanics: Innovations in Applied and Theoretical Rock Mechanics, International Society for Rock Mechanics, Lisbon, paper 806.

Dorador, L 2016, Experimental Investigation of the Effect of Broken Ore Properties on Secondary Fragmentation During Block Caving, $\mathrm{PhD}$ thesis, The University of British Columbia, Vancouver.

Eadie, B 2003, A Framework for Modeling Fragmentation in Block Caving, PhD thesis, The University of Queensland, Brisbane.

Hardin, B 1985, 'Crushing of soil particles', Journal of Geotechnical Engineering, vol. 111, no. 10, pp. 1177-1192.

Laubscher, D 1994, 'Cave mining - the state of the art', Journal of the South African Institute of Mining Metallurgy, vol. 94, no. 10, pp. 279-293. 
